Vol. 2, No. 1, Desember 2021

\title{
PENINGKATAN PENGETAHUAN TENTANG PENCATATAN KEUANGAN SEDERHANA MENUJU TERTIB PEMBUKUAN BAGI PELAKU UMKM NASABAH PANTAS ULAMM PT. PNM CABANG TEGAL
}

\author{
Fitri Amaliyah \\ Politeknik Harapan Bersama \\ fitri.amaliyah@poltektegal.ac.id \\ Imam Hasan \\ Politeknik Harapan Bersama \\ imamhasan@poltektegal.ac.id \\ Kholifah Fil Ardhi \\ Politeknik Harapan Bersama \\ kholifahfilardhi@gmail.com \\ Yeni Priatna Sari \\ Politeknik Harapan Bersama \\ yeni.priatna@gmail.com
}

Info Artikel

Diterima:

04-11-2021

Direvisi:

24-12-2021

Diterbitkan:

24-12-2021
Abstrak

Program Pengembangan Kapasitas Usaha dan
Pengembangan Kelompok (PKU-PK) yang
diselenggarakan oleh PNM bertujuan memberikan
pendampingan kepada pelaku UMKM yang merupakan
nasabah binaan PNM. Program tersebut memiliki konsep
mengkombinasikan bisnis pembiayaan dan
pendampingan usaha untuk meningkatkan kualitas
pengelolaan usaha yang dilakukan secara
berkelanjutan. Metode yang digunakan dalam
pengabdian yaitu pemberian materi pengenalan
pembukuan secara sederhana dan diskusi tanya jawab
melalui whatsapp grup. Tahap pertama, memberikan
motivasi tentang pentingnya pembuatan laporan
keuangan kepada nasabah binaan PNM dan selanjutnya
diberikan materi tentang penyusunan laporan keuangan
secara sederhana dan contoh soal kasusnya. Tahap
selanjutnya diskusi tanya jawab. Secara garis besar
kegiatan ini dapat dinyatakan berhasil dilihat dari
nasabah Binaan PNM yang antusias bertanya dan mau
menerapkan materi yang sudah disampaikan dalam
pelatihan. Kegiatan pelatihan ini juga dapat
berkontribusi dalam peningkatan pengetahuan dan


wawasan mengenai proses penyusunan laporan keuangan secara sederhana. Saran yang dapat diberikan adalah adanya pelatihan lanjutan mengenai cara menyusun laporan laba rugi.

Kata Kunci: UMKM, Pembukuan Sederhana, Nasabah Binaan PNM

DOI: 10.29303 /abdimassangkabira.v2i1.69

\section{Pendahuluan}

Pelaku Usaha Mikro Kecil dan Menengah (UMKM) dihadapkan adanya perkembangan industri yang sangat cepat dan dinamis. Hal ini memaksa para pelaku UMKM untuk dapat mempertahankan daya saingnya dalam mengembangkan usahanya. Di Indonesia, UMKM memiliki peran yang strategis dalam pembangunan ekonomi nasional antara lain yaitu dalam pertumbuhan ekonomi, menciptakan lapangan kerja dan pemerataan pendapatan (Prativi et al., 2019).

Pelaku usaha di Indonesia sebagian besar merupakan pemilik usaha mikro kecil dan menengah. UMKM memiliki karakter dengan merintis dan menjalankan bisnis usahanya menggunakan modal yang minimal (Wardiningsih et al., 2020). Kementerian Koperasi dan UMKM mengungkapkan hasil Arah Kebijakan dan Program Pengembangan KUKM 2020-2024 masih rendahnya UMKM dalam memperoleh pendanaan. Sebagian besar UMKM belum memiliki akses pendanaan baik dari perbankan maupun non bank untuk modal usaha. Sulitnya UMKM untuk memperoleh pendanaan disebabkan karena pemilik usaha belum mampu menyajikan kondisi perkembangan usahanya salah satunya penyusunan laporan keuangan.

PT Permodalan Nasional Madani (PNM) merupakan badan usaha milik negara yang bergerak di bidang jasa keuangan. PNM memiliki tugas khusus untuk memajukan ekonomi kerakyatan dengan memberikan modal finansial berupa pembiayaan dan modal intelektual berupa pelatihan kepada pelaku usaha mikro, kecil dan menengah (UMKM). Program PNM dalam memberikan pembiayaan kepada pelaku UMKM terdiri dari Unit Layanan Modal Mikro (UlaMM) dan Membina Ekonomi Keluarga Sejahtera (Mekaar) yang diberikan kepada perempuan prasejahtera pelaku usaha ultra mikro.

Pengembangan Kapasitas Usaha (PKU) merupakan salah satu program sebagai komitmen PNM dalam memberikan pendampingan dan pembinaan kepada nasabah yaitu nasabah UlaMM Pantas. Pelatihan diberikan kepada ibu-ibu yang merupakan nasabah PNM dengan tujuan memberikan motivasi, meningkatkan pengetahuan dan ketrampilan dalam menjalankan usahanya. Pelatihan yang diberikan kepada nasabah PNM adalah pelatihan pencatatan keuangan sederhana. 


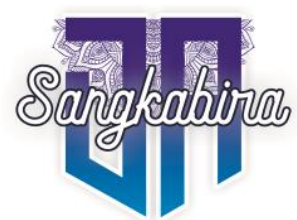

Vol. 2, No. 1, Desember 2021

Berdasarkan hasil pengamatan nasabah PNM UlaMM Pantas merupakan kelompok usaha ultra mikro yang memiliki modal kecil dan usahanya belum lama dijalankan. Kendala yang sering dihadapi oleh pelaku UMKM yaitu dalam pengelolaan keuangan, padahal pengelolaan keuangan merupakan aspek penting dalam menjalankan bisnisnya salah satunya dalam memperoleh kemudahaan pembiayaan. Pelaku usaha mikro masih sangat jarang yang membuat laporan keuangan yang sesuai standar akuntansi keuangan, baru sebatas pencatatan pembukuan secara sederhana.

Pembukuan secara sederhana merupakan proses sistematis dalam penyusunan pencatatan keuangan sehingga dapat informasi yang dihasilkan dapat untuk mengetahui perkembangan usahanya (Maharani \& Hasanah, 2020). Nasabah Ulamm Pantas belum mampu untuk melakukan pembukuan secara sederhana. Hal tersebut dikarenakan karena terbatasnya pengetahuan yang dimiliki oleh pemilik terkait pemahaman tentang akuntansi dan terbatasnya sumber daya manusia sehingga dalam menjalankan usahanya mereka merasa kesulitan salah satunya tidak dapat mengetahui berapa laba yang diperoleh.

Masalah utama yang dialami oleh nasabah Ulamm Pantas adalah belum adanya pencatatan keuangan meskipun pencatatan keuangan secara sederhana dan rendahnya pengetahuan tentang akuntansi. Selain itu, dengan adanya pandemi covid-19 juga menyebabakan penurunan penjualan sehingga modal yang dimiliki semakin berkurang sehingga harus ada strategi untuk mempertahankan usahanya. Kondisi tersebut memperkuat alasan untuk diadakannya upaya pelatihan peningkatan pengetahuan tentang pencatatan keuangan sederhana menuju tertib pembukuan bagi pelaku UMKM Nasabah UlaMM Pantas Cabang Tegal.

\section{Metode}

Pelaksanaan Pengabdian Kepada Masyarakat ini dilakukan dengan menggunakan metode ceramah, tutorial dan diskusi melalui whatsapp grup di masing-masing kelompok. Adapun sistematika pelaksanaan kegiatan pengabdian adalah sebagai berikut:

1) Metode Ceramah

Pada tahap ini peserta diberikan motivasi tentang pentingnya menyusun laporan keuangan meskipun berawal dari pembukuan sederhana yang bertujuan untuk mengetahui kondisi usahanya yang telah dibagi sesuai grup melalui whatsapp grup. Selanjutnya peserta dikenalkan nama akun dan nomor akun agar mengetahui akun apa saja yang dibutuhkan pada saat membuat pembukuan secara sederhana. Peserta juga diberikan gambaran tentang langkah-langkah menyusun kartu kas, kartu piutang dan kartu utang.

2) Metode Tutorial 
Pemateri memberikan materi dan mempraktekan cara mengerjakan soal transaksi yang terkait dengan penerimaan dan pengeluaran kas, penjualan dan pembelian barang dagang selanjutnya peserta pelatihan mempraktekan langsung secara mandiri sesuai masing-masing usahanya.

3) Metode Diskusi

Pemateri menjelaskan tentang mencatat transaksi secara mudah ke dalam kartu kas, kartu utang dan kartu piutang serta peserta pelatihan diberikan kesempatan untuk mendiskusikan permasalahan yang berkaitan dengan permasalahan kasus yang ditemukan pada saat melakukan transaksi sehari-hari di usahanya masing-masing.

\section{Hasil}

Kegiatan pengabdian masyarakat ini di hadiri oleh 6 kelompok wilayah UMKM nasabah UlaMM Pantas PT PNM yang terdiri dari wilayah pertama meliputi Talang, Tegal dan Slawi. Wilayah kedua meliputi Brebes Jatibarang, Brebes Kota, dan Ketanggungan. Wilayah ketiga meliputi Randudongkal, dan Bojong. Wilayah keempat meliputi Pemalang, Petarukan, dan Comal. Wilayah kelima meliputi Kajen dan Kedungwuni dan wilayah yang keenam meliputi Wiradesa dan Batang. Kegiatan ini disambut positif oleh para siswa. Berikut ini adalah urutan acara pengabdian masyarakat yang diselenggarakan secara virtual melalui whatsapp grup 22-23 September 2021:

Tabel 1. Susunan Acara

\begin{tabular}{ccc}
\hline \multicolumn{1}{c}{ NO } & ACARA & KETERANGAN \\
\hline Rabu, 22 September 2021 & MC \\
\hline 1. & Pembukaan & Ananto Seno \\
\hline 2. & Sambutan dari Pimpinan PNM & Tim PKM \\
\hline 3. & Penjelasan Materi & Tim PKM \\
\hline 4. & Penjelasan Contoh Kasus & Tim PKM \\
\hline 5. & Diskusi dan Tanya Jawab & MC \\
\hline 6. & Penutup & \\
\hline
\end{tabular}

Sabtu, 23 September 2021

\begin{tabular}{clc} 
1. & Pembukaan & MC \\
\hline 2. & Sambutan dari Pimpinan PNM & Ananto Seno \\
\hline 3. & Penjelasan Materi & Tim PKM \\
\hline 4. & Penjelasan Contoh Kasus & Oleh Tim PKM \\
\hline 5. & Diskusi dan Tanya Jawab & Tim PKM \\
\hline 6. & Penutup & MC
\end{tabular}

Pemaparan materi yang dilakukan oleh 1 (satu) dosen tim PKM disetiap kelompok yang terdiri dari beberapa wilayah nasabah UlaMM Pantas PT PNM Cabang Tegal. Adapun pembagian kelompok narasumbernya adalah sebagai berikut: 


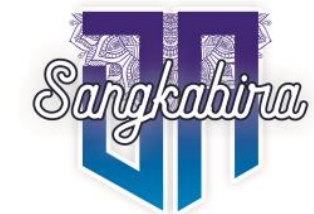

Vol. 2, No. 1, Desember 2021
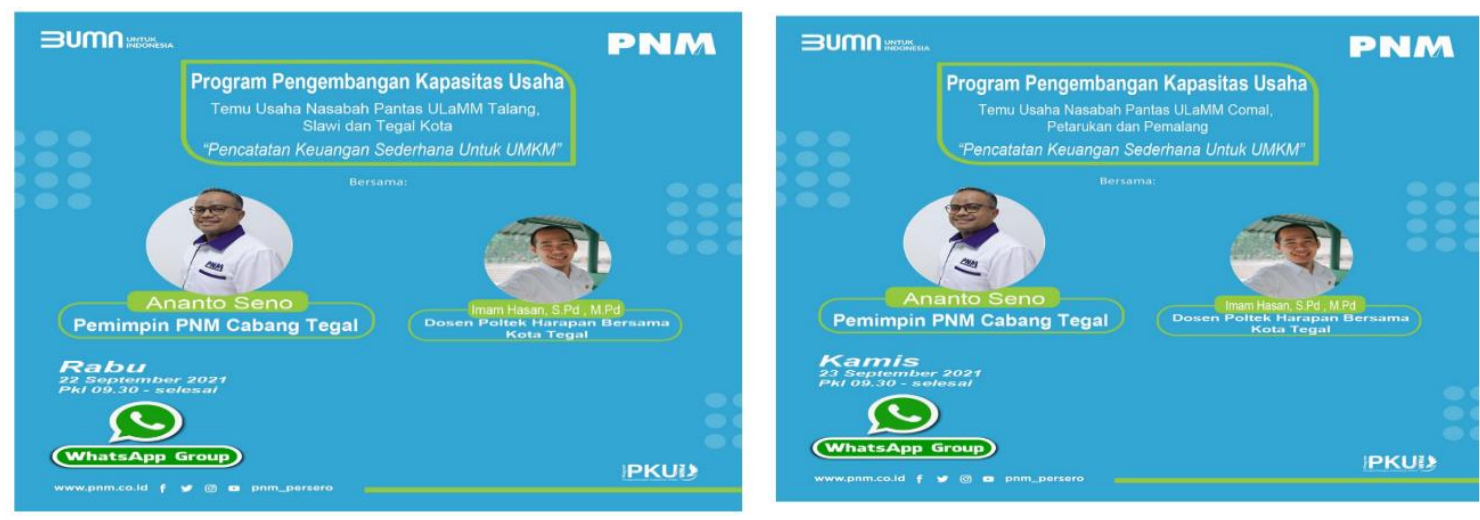

Gambar 1. Sesi Pertama dan Keempat Pemaparan Materi
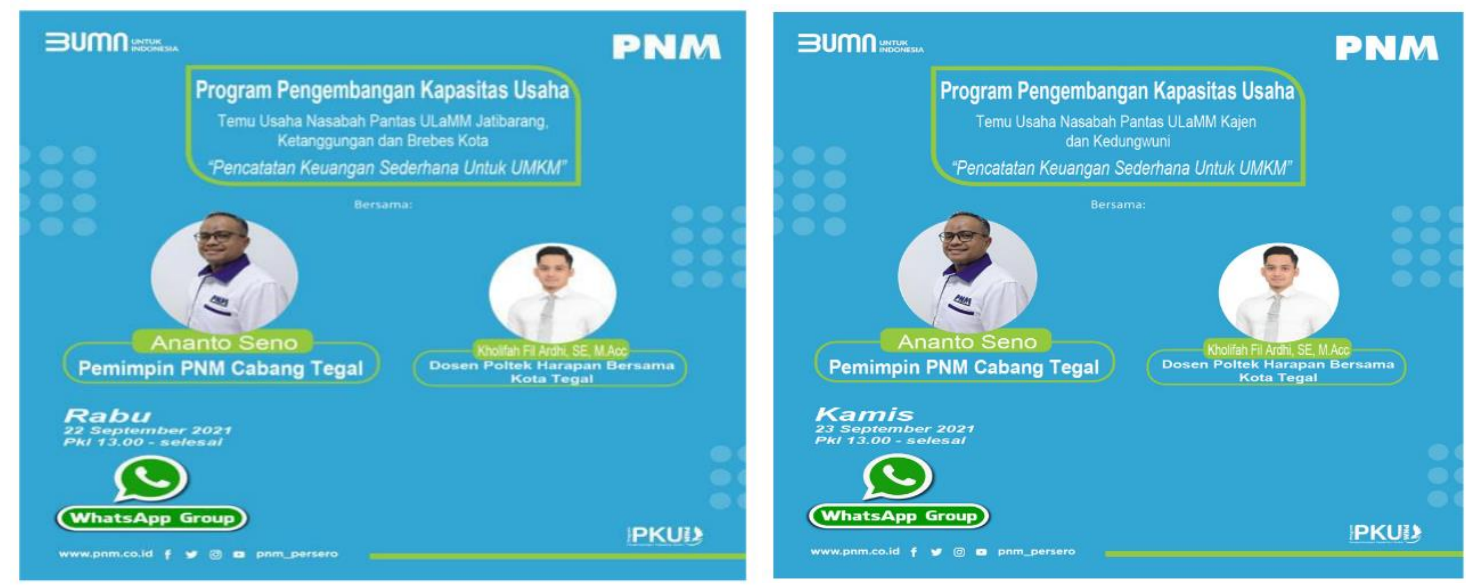

Gambar 2. Sesi Kedua dan Kelima Pemaparan Materi
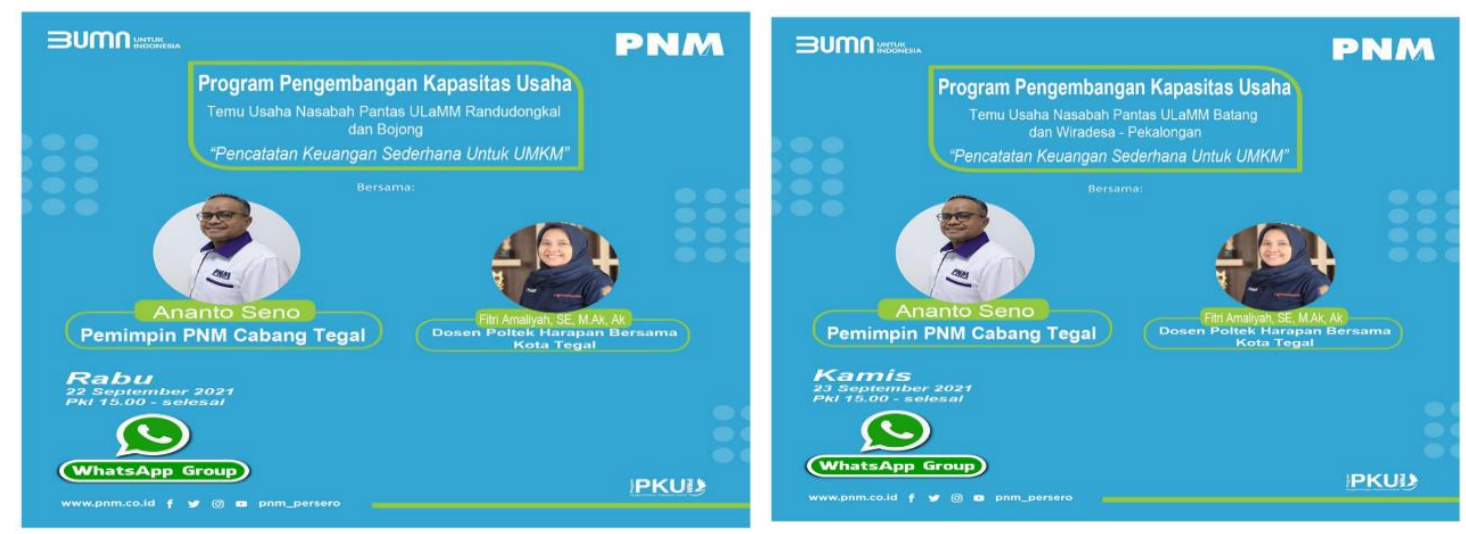

Gambar 3. Sesi Ketiga dan Keenam Pemaparan Materi

Berdasarkan hasil pengamatan, diskusi dan tanya jawab selama kegiatan berlangsung melalui whatsapp grup kegiatan pengabdian masyarakat ini memberikan hasil yaitu meningkatnya pengetahuan dan 
pemahaman nasabah dalam mengenal nama akun dan nomor akun dan contoh-contoh nama akunnya. Selain itu, juga dapat meningkatnya ketrampilan nasabah UlaMM Pantas PT PNM dalam dalam mengerjakan kartu kas, kartu utang dan kartu piutang. Adapun hasil diskusi dengan para nasabah UlaMM Pantas PT PNM Cabang Tegal adalah sebagai berikut:
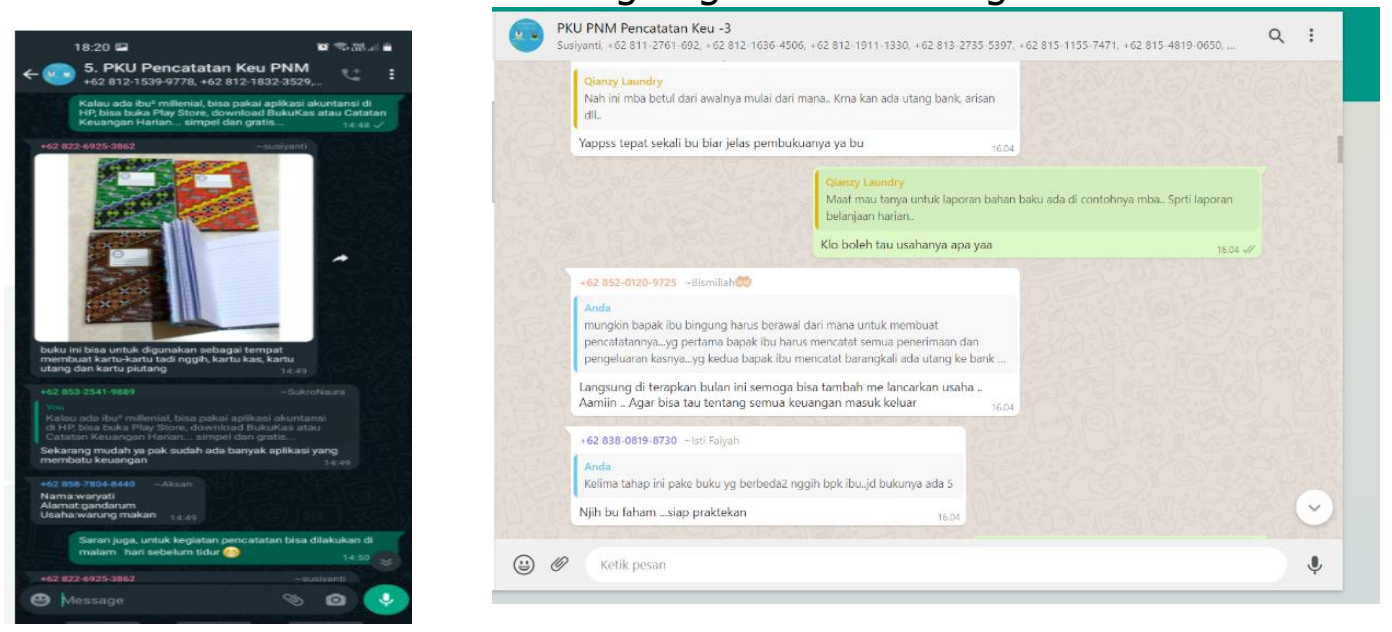

Gambar 4. Sesi Diskusi dan Tanya Jawab

\section{Diskusi}

Kegiatan Pengabdian Kepada Masyarakat (PKM) Mitra ini secara khusus bertujuan untuk meningkatkan pengetahuan dan wawasan dalam menyusun laporan keuangan bagi nasabah UlaMM Pantas PT PNM Cabang Tegal. Kegiatan penyampaian materi dilaksanakan pada tanggal 22 dan 23 September 2021 melalui whatsapp grup, dihadiri oleh 6 kelompok nasabah UlaMM Pantas PT PNM Cabang Tegal. Kegiatan ini mendapatkan respon positif oleh peserta karena peserta memperoleh pengetahuan tentang cara mencatat transaksi ke dalam kartu kas, kartu utang dan kartu piutang dengan cepat dan mudah sehingga dapat memberikan hasil yang maksimal.

Kegiatan di hari pertama diawali dengan kelompok pertama meliputi wilayah Talang, Tegal dan Slawi. Tahap kedua dilanjutkan kelompok kedua meliputi Brebes Jati Barang, Brebes Kota dan Ketanggungan. Tahap ketiga dilanjutkan kepada kelompok nasabah meliputi wilayah Randu Dongkal dan Bojong. Tahap keempat meliputi wilayah Pemalang, Petarukan, dan Comal. Dilanjutkan kelompok kelima meliputi Kajen dan Kedungwuni. Dan terakhir kelompok keenam meliputi Wiradesa dan Batang. Kegiatan ini diawali memberikan motivasi kepada nasabah UlaMM Pantas PT PNM Cabang Tegal. Selanjutnya peserta diberikan paparan materi tentang pengenalan nomor akun dan nama akun serta contoh-contoh akunnya. Kemudian dilanjutkan dengan memberikan contoh soal kasus terkait dengan materi kartu kas, kartu piutang dan kartu utang dan ditutup dengan sesi diskusi 


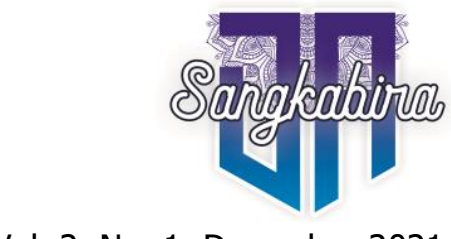

Vol. 2, No. 1, Desember 2021

tanya jawab.

Kegiatan pendampingan dan pembinaan nasabah UlaMM Pantas Cabang Tegal adalah kegiatan rutin yang diselenggaran dalam program Pengembangan Kapasitas Usaha dan Pengembangan Kelompok (PKU-PK) dibutuhkan oleh dunia industri. Salah satu program kerjasama yang dilaksanakan oleh Prodi DIII Akuntansi Politeknik Harapan Bersama Tegal dengan PT Permodalan Nasional Madani (PT PNM) Cabang Tegal yaitu dengan memberikan pelatihan dan pendampingan kepada nasabah PT PNM dalam menyusun laporan keuangan yang diikuti oleh nasabah UlaMM PT PNM Cabang Tegal.

\section{Kesimpulan}

Pelaksanaan pengabdian kepada masyarakat (PKM) mitra ini dalam meningkatkan pengetahuan dan ketrampilan nasabah UlaMM Pantas PT PNM Cabang Tegal dalam penyusunan laporan keuangan yang telah berjalan secara rutin sesuai dengan jadwal yang diberikan. Kerjasama yang terjalin dengan baik antara Prodi DIII Akuntansi dengan PT PNM Cabang Tegal memberikan dampak positif bagi kedua pihak. Berdasarkan kegiatan pengabdian masyarakat yang telah dilaksanakan dapat disimpulkan bahwa:

a. Meningkatnya pemahaman nasabah UlaMM Pantas PT PNM Cabang Tegal tentang pentingnya menyusun laporan keuangan.

b. Memberikan bekal kepada nasabah UlaMM Pantas PT PNM Cabang Tegal agar lebih siap untuk mulai tertib dalam penyusunan laporan keuangan.

Berikut ini beberapa masukan yang diberikan kepada pihak mitra agar pelaksanaan pelatihan lebih maksimal antara lain:

a. Pihak PT PNM Cabang Tegal perlu memberikan pelatihan yang lebih sering waktunya sehingga nasabah mamiliki pengetahuan yang lebih luas.

b. Jumlah tatap muka atau disarankan ditambah agar materi yang disampaikan dapat diserap lebih maksimal lagi.

\section{Pengakuan/Acknowledgements}

Penulis mengucapkan terima kasih kepada Prodi DIII Akuntansi Politeknik Harapan Bersama Tegal yang telah memberi dukungan terhadap kegiatan PkM ini. 


\section{Daftar Referensi}

Maharani, D., \& Hasanah, I. (2020). Pelatihan Pembukuan Sederhana Bagi Usaha Kecil Untuk Meningkatkan Pemahaman Pencatatan Keuangan Di Desa Puntik Tengah Kecamatan Mandastana Kabupaten Barito Kuala. 2(1), 1-6.

Prativi, A., Agustina, D., \& Nasehati, S. (2019). Pelatihan Pembukuan Sederhana UMKM Pada Anggota KSU Hasta Mandiri Kota Magelang. Prosiding Seminar Nasional Mewujudkan Masyarakat Madani Dan Lestari Seri 9, 53(9), 1-5.

Wardiningsih, R., Wahyuningsih, B. Y., Sugianto, R., \& Mataram, U. T. (2020). Pelatihan Pembukuan Sederhana Bagi Pelaku Usaha Kecil ( Mikro ) Di Dusun Bore Desa Kopang. Jurnal Pendidikan Dan IImu Sosial, 2, 163-172. 